\title{
DPA-714, a New Translocator Protein-Specific Ligand: Synthesis, Radiofluorination, and Pharmacologic Characterization
}

\author{
Michelle L. James ${ }^{1}$, Roger R. Fulton ${ }^{2}$, Johnny Vercoullie ${ }^{3}$, David J. Henderson ${ }^{2}$, Lucette Garreau ${ }^{3}$, Sylvie Chalon ${ }^{3}$, \\ Frederic Dolle ${ }^{4}$, Silvia Selleri ${ }^{5}$, Denis Guilloteau ${ }^{3}$, and Michael Kassiou ${ }^{6-8}$ \\ ${ }^{I}$ Department of Pharmacology, University of Sydney, Sydney, New South Wales, Australia; ${ }^{2}$ Department of PET and Nuclear Medicine, \\ Royal Prince Alfred Hospital, Camperdown, New South Wales, Australia, ${ }^{3}$ INSERM U619, Tours, France; Université François-Rabelais \\ de Tours, Tours, France; ${ }^{4}$ CEA, Service Hospitalier Frédéric Joliot, Institut d'Imagerie Biomedicale, Orsay, France; ${ }^{5}$ Dipartimento di \\ Scienze Farmaceutiche, Università di Firenze, Firenze, Italy; ${ }^{6}$ Discipline of Medical Radiation Sciences, University of Sydney, Sydney, \\ New South Wales, Australia; ${ }^{7}$ Brain and Mind Research Institute, University of Sydney, Camperdown, New South Wales, Australia; and \\ ${ }^{8}$ School of Chemistry, University of Sydney, Sydney, New South Wales, Australia
}

The translocator protein (18 kDa) (TSPO), formerly known as the peripheral benzodiazepine receptor, is dramatically upregulated under pathologic conditions. Activated microglia are the main cell type expressing the TSPO at sites of central nervous system pathology. Radioligands for the TSPO can therefore measure active disease in the brain. This article details the synthesis, radiofluorination, and pharmacologic evaluation of a new TSPOspecific pyrazolopyrimidine, DPA-714. Methods: The affinity of DPA-714 for the TSPO was measured in rat kidney membranes with ${ }^{3} \mathrm{H}-\mathrm{PK} 11195$. The in vitro functional activity of DPA-714 was measured in a steroidogenic assay in which the ability of DPA-714 to increase pregnenolone synthesis was measured with rat 66 glioma cells. The radiofluorination of DPA-714 was achieved by nucleophilic ${ }^{18} \mathrm{~F}$-fluoride displacement of the tosylate precursor. ${ }^{18} \mathrm{~F}-\mathrm{DPA}-714$ was assessed in rats harboring unilateral quinolinic acid (QA) lesions. In addition, pretreatment experiments were performed with PK11195 (5 mg/kg), DPA$714(1 \mathrm{mg} / \mathrm{kg})$, and DPA-713 (1 mg/kg). The in vivo binding and biodistribution of ${ }^{18} \mathrm{~F}-\mathrm{DPA}-714$ were determined in a baboon with PET. Experiments involving presaturation with PK11195 $(1.5 \mathrm{mg} / \mathrm{kg})$ and displacement with DPA-714 (1 mg/kg) were conducted to evaluate the specificity of radioligand binding. Results: In vitro binding studies revealed that DPA-714 displayed a high affinity for the TSPO (dissociation constant, $7.0 \mathrm{nM}$ ). DPA-714 stimulated pregnenolone synthesis at levels $80 \%$ above the baseline. ${ }^{18} \mathrm{~F}-\mathrm{DPA}-714$ was prepared at a $16 \%$ radiochemical yield and a specific activity of $270 \mathrm{GBq} / \mu \mathrm{mol}$. In rats harboring unilateral QA lesions, an 8-fold-higher level of uptake of ${ }^{18} \mathrm{~F}$-DPA-714 was observed in the ipsilateral striatum than in the contralateral striatum. Uptake in the ipsilateral striatum was shown to be selective because it was inhibited to the level in the contralateral striatum in the presence of PK11195, nonlabeled DPA-714, or DPA-713. PET studies demonstrated rapid penetration and good retention of ${ }^{18} \mathrm{~F}-\mathrm{DPA}-714$ in the baboon

Received Aug. 7, 2007; revision accepted Jan. 16, 2008.

For correspondence or reprints contact: Michael Kassiou, Brain and Mind Research Institute, 100 Mallett St., Camperdown, New South Wales 2050, Australia.

E-mail: M.Kassiou@usyd.edu.au

COPYRIGHT @ 2008 by the Society of Nuclear Medicine, Inc. brain. Pretreatment with PK11195 effectively inhibited the uptake of ${ }^{18} \mathrm{~F}$-DPA-714 in the whole brain, indicating its selective binding to the TSPO. The injection of nonlabeled DPA-714 20 min after the injection of ${ }^{18} \mathrm{~F}-\mathrm{DPA}-714$ resulted in radioligand washout, demonstrating the reversibility of ${ }^{18} \mathrm{~F}-\mathrm{DPA}-714$ binding. Conclusion: ${ }^{18} \mathrm{~F}-\mathrm{DPA}-714$ is a specific radioligand for the TSPO, displaying promising in vivo properties and thus warranting further investigation.

Key Words: PET; translocator protein; ${ }^{18} \mathrm{~F}$; DPA-714; microglia J Nucl Med 2008; 49:814-822

DOI: 10.2967/jnumed.107.046151

$\mathbf{T}$ he translocator protein $(18 \mathrm{kDa})(\mathrm{TSPO})$ is a highly hydrophobic protein located mainly on the outer mitochondrial membrane $(1,2)$. Originally, the TSPO was identified in peripheral tissue as an alternative binding site for diazepam (3) and, for this reason, was initially known as the peripheral benzodiazepine receptor. Later studies revealed that this receptor bound molecules other than benzodiazepines and was also present at low levels in the central nervous system. This information highlighted the misleading nature of the term "peripheral benzodiazepine receptor" and justified the need for a new name to better capture the cellular location and tissue-specific roles of this receptor. Since the main structure-function relationships of this entity involve the binding and transport of specific ligands, including cholesterol and porphyrin, the name "TSPO" was proposed (4).

The TSPO is involved in several important cellular processes, including apoptosis (5), regulation of cellular proliferation (6), immunomodulation (7), heme biosynthesis (8), and production of steroid hormones (9). The most characterized functional role of the TSPO is its ability to facilitate the transport of cholesterol from the outer to the inner mitochondrial membrane, where it is metabolized into pregnenolone by cytochrome $\mathrm{P}-450$ side-chain cleavage, a process that 
leads to the production of various steroids $(9,10)$. Highaffinity TSPO ligands, both endogenous and exogenous, can stimulate this process, resulting in increased concentrations of steroids in the brain. For this reason, TSPO ligands are thought to hold therapeutic potential for treating memory and stress-related disorders $(11,12)$.

Consistent with its key involvement in steroidogenesis, the TSPO is most densely distributed in steroid-producing endocrine organs $(1,13)$. In the healthy brain, TSPO expression is negligible, but under neuroinflammatory conditions, TSPO density is markedly increased (14). In vitro and in vivo studies have proven the main cell type expressing the TSPO at sites of central nervous system pathology to be activated microglia $(15,16)$, the resident brain macrophages $(17,18)$. Microglial activation is known to occur during the initial stages of most neurologic disorders and even precedes neurodegeneration. Because TSPO expression reflects the extent of microglial activation, specific radioligands for the TSPO can serve as indicators of early brain disease (18).

At present, only a few TSPO-specific radioligands are available for use in PET studies. ${ }^{11} \mathrm{C}-(R)$-PK11195 has long been considered the standard for TSPO imaging; however, its poor signal-to-noise ratio and low brain permeability limit its accuracy and usefulness (19). Several new TSPO-specific ligands, namely, ${ }^{11} \mathrm{C}$-DAA1106, ${ }^{18} \mathrm{~F}$-FEDAA1106, and ${ }^{11} \mathrm{C}$ PBR28, have been described and reported to display good in vivo properties in rodent brains $(20,21) .{ }^{11} \mathrm{C}$-DAA1 106 and ${ }^{18}$ F-FEDAA1106 have also been shown to display highly specific in vivo uptake in primate brains $(22) ;{ }^{18} \mathrm{~F}$-FEDAA1106 was recently evaluated in human PET studies (23). Although these promising TSPO-specific ligands have newly emerged, there remains a considerable gap in information needed to completely characterize the TSPO. By synthesizing a large set of structurally and functionally diverse radioligands, we hoped to gain a better understanding of the TSPO, its therapeutic potential, and the possible existence of subtypes.

In 2001, a series of TSPO-specific pyrazolopyrimidine ligands were reported (24). Recently, one of these ligands, $\mathrm{N}, \mathrm{N}$-diethyl-2-(2-(4-methoxyphenyl)-5,7-dimethylpyrazolo [1,5-a]pyrimidin-3-yl)acetamide (DPA-713), was labeled with ${ }^{11} \mathrm{C}$. PET studies showed that ${ }^{11} \mathrm{C}$-DPA-713 selectively and specifically bound the TSPO in normal baboon brains (25). Since then, ${ }^{11}$ C-DPA-713 has been labeled more efficiently with methyl triflate (26) and evaluated in rat models of disease (27). These encouraging results prompted us to synthesize an ${ }^{18} \mathrm{~F}$-labeled derivative of DPA-713.

The aims of this study were to synthesize the fluoroethoxy analog DPA-714, label it with ${ }^{18} \mathrm{~F}$, and evaluate ${ }^{18} \mathrm{~F}$ DPA-714 in a neuroinflammatory rodent model and in vivo in a normal baboon by using PET.

\section{MATERIALS AND METHODS}

\section{General}

All chemicals and solvents were of high grade and were purchased from Aldrich, except as otherwise stated. ${ }^{3} \mathrm{H}-\mathrm{PK} 11195$, which was used for in vitro binding, was purchased from DupontNew England Nuclear. PK11195 used for PET studies was purchased from Tocris, and PK11195 used for ex vivo studies was obtained from Sigma. Melting points were measured with a Reichert melting point stage and are uncorrected. Proton nuclear magnetic resonance $\left({ }^{1} \mathrm{H} \mathrm{NMR}\right)$ spectra were recorded with a $300-\mathrm{MHz}$ Varian Gemini instrument. Chemical shifts $(\delta)$ were reported in parts per million downstream from internal tetramethylsilane. Multiplicities were reported as s (singlet), d (doublet), dd (doublet of doublets), $\mathrm{m}$ (multiplet), and the observed coupling constant $(J, \mathrm{~Hz})$. Mass spectrometry was performed with a Thermo Finnigan Polaris Q gas chromatography-mass spectrometry instrument. Thin-layer chromatography was performed with aluminum-backed plates (Lomb Scientific) precoated with silica gel $60\left(\mathrm{~F}_{254}\right)$ and visualized with UV fluorescence ( 254 or $365 \mathrm{~nm}$ ). Column chromatography was performed with Merck silica gel 60 (230-400 mesh). All radiosyntheses were carried out with $\mathrm{MX}_{\mathrm{FDG}}$ reagent kits from $\mathrm{ABX}$ Chemicals, but with the removal of the buffer solution and the aqueous $\mathrm{NaOH}$ syringe. The eluent vials contained $22.0 \mathrm{mg}$ of Kryptofix-222, $7.0 \mathrm{mg}$ of $\mathrm{K}_{2} \mathrm{CO}_{3}, 300 \mu \mathrm{L}$ of acetonitrile, and $300 \mu \mathrm{L}$ of water. The reagent vials contained $7 \mathrm{~mL}$ of acetonitrile, $5 \mathrm{~mL}$ of ethanol, and $2 \mathrm{~mL}$ of ethanol.

\section{Chemistry}

N,N-Diethyl-2-(2-[4-(2-Fluoroethoxy)-Phenyl]-5,7-DimethylPyrazolo[1,5-a]Pyrimidin-3-yl)-Acetamide (DPA-714). Diisopropyl azodicarboxylate (DIAD, $190 \mathrm{mg}, 0.94 \mathrm{mmol}$ ) was added to a solution of $\mathrm{N}, \mathrm{N}$-diethyl-2-(2-(4-hydroxyphenyl)-5,7-dimethylpyrazolo [1,5-a]pyrimidin-3-yl)ethanamide (compound 1) (25) (150 mg, 0.43 $\mathrm{mmol}$ ), triphenylphosphine (274 $\mathrm{mg}, 0.94 \mathrm{mmol}$ ), and 2-fluoroethanol (60 mg, $0.94 \mathrm{mmol})$ in dry $N, N$-dimethylformamide (DMF) $(6 \mathrm{~mL})$. The reaction mixture was stirred at room temperature for $48 \mathrm{~h}$ and concentrated with a rotary evaporator $\left(95^{\circ} \mathrm{C}, 20\right.$ millibars $)$. The resulting crude oil was dissolved in $\mathrm{CHCl}_{3}(40 \mathrm{~mL})$, and the mixture was washed with water $(3 \times 20 \mathrm{~mL})$ to remove DMF. The organic layer was collected and dried over anhydrous $\mathrm{Na}_{2} \mathrm{SO}_{4}$. The solvent was removed under vacuum, and the residue was purified by column chromatography $\left(\mathrm{CHCl}_{3}\right.$ :methanol $[\mathrm{MeOH}], 80: 1$, v/v, as the eluent) to yield DPA-714 (80 $\mathrm{mg}, 0.20 \mathrm{mmol})$ as pale yellow crystals at a $47 \%$ yield and with a melting point of $160^{\circ} \mathrm{C}-163^{\circ} \mathrm{C}$. ${ }^{1} \mathrm{H} \mathrm{NMR}\left(\mathrm{CDCl}_{3}, 300 \mathrm{MHz}\right) \delta: 7.78(\mathrm{~d}, 2 \mathrm{H}, J=9.0 \mathrm{~Hz}), 6.52$ $\left(\mathrm{s},{ }^{1} \mathrm{H}\right), 7.01(\mathrm{~d}, 2 \mathrm{H}, J=9.0 \mathrm{~Hz}), 4.78(\mathrm{dt}, 2 \mathrm{H}, J=4,47 \mathrm{~Hz}), 4.26$ (dt, 2H, $J=4,28 \mathrm{~Hz}), 3.93$ (s, 2H), 3.39-3.51 (m, 4H), 2.75 (s, 3H), 2.56 (s, 3H), 1.09-1.27 (m, 6H). Found: C, 66.70; H, 6.60; N, 13.14. Mass spectrum: chemical ionization (CI), $m / z 399(\mathrm{M}+1)$.

Toluene-4-Sulfonic Acid 2-[4-(3-Diethylcarbamoylmethyl-5,7Dimethyl-Pyrazolo-[1,5-a]Pyrimidin-2-yl)-Phenoxy]-Ethyl Ester (Compound 2). For step 1, fresh silver oxide (350 mg, $1.5 \mathrm{mmol}$ ), p-toluenesulfonyl chloride (210 $\mathrm{mg}, 1.1 \mathrm{mmol})$, and potassium iodide (33 mg, $0.2 \mathrm{mmol}$ ) were added to a stirred solution of 1,2ethanediol $(62 \mathrm{mg}, 1 \mathrm{mmol})$ in dichloromethane $(10 \mathrm{~mL})$. The reaction mixture was stirred at room temperature for $2 \mathrm{~h}$, filtered through a pad of celite, and washed with ethyl acetate. The solvent was removed, and the crude product was purified by column chromatography $\left(\mathrm{CH}_{2} \mathrm{Cl}_{2}: \mathrm{MeOH}, 40: 1\right.$, v/v, as the eluent) to yield toluene-4-sulfonic acid 2-hydroxy-ethyl ester as an oil at a $46 \%$ yield. ${ }^{1} \mathrm{H} \mathrm{NMR}\left(\mathrm{CDCl}_{3}, 300 \mathrm{MHz}\right) \delta: 7.81(\mathrm{~d}, 2 \mathrm{H}, J=8.1 \mathrm{~Hz})$, $7.36(\mathrm{~d}, 2 \mathrm{H}, J=8.1 \mathrm{~Hz}), 4.15(\mathrm{~d}, 2 \mathrm{H}, J=9.0 \mathrm{~Hz}), 3.82(\mathrm{~d}, 2 \mathrm{H}$, $J=9.0 \mathrm{~Hz}), 2.46(\mathrm{~s}, 3 \mathrm{H})$.

For step 2, DIAD $(0.48 \mathrm{~mL}, 2.4 \mathrm{mmol})$ was added to a solution of compound 1 (25) (400 mg, $1.1 \mathrm{mmol}$ ), triphenylphosphine (637 
$\mathrm{mg}, 2.4 \mathrm{mmol}$ ), and toluene-4-sulfonic acid 2-hydroxy-ethyl ester (525 mg, $2.4 \mathrm{mmol})$ in dry DMF $(10 \mathrm{~mL})$. The reaction mixture was stirred for $20 \mathrm{~h}$ at room temperature and concentrated with a rotary evaporator $\left(95^{\circ} \mathrm{C}, 20\right.$ millibars $)$. The residue was purified by column chromatography $\left(\mathrm{CHCl}_{3}: \mathrm{MeOH}, 80: 1\right.$, v/v, as the eluent) to yield compound 2 ( $363 \mathrm{mg}, 0.66 \mathrm{mmol}$ ) as light yellow crystals at a $60 \%$ yield and with a melting point of $128^{\circ} \mathrm{C}-132^{\circ} \mathrm{C} .{ }^{1} \mathrm{H}$ NMR $\left(\mathrm{CDCl}_{3}, 300 \mathrm{MHz}\right) \delta: 7.83(\mathrm{~d}, 2 \mathrm{H}, J=8.1 \mathrm{~Hz}), 7.74(\mathrm{~d}, 2 \mathrm{H}$, $J=9.0 \mathrm{~Hz}), 7.35(\mathrm{~d}, 2 \mathrm{H}, J=8.1 \mathrm{~Hz}), 6.86(\mathrm{~d}, 2 \mathrm{H}, J=9.0 \mathrm{~Hz})$, $6.52\left(\mathrm{~s},{ }^{1} \mathrm{H}\right), 4.37(\mathrm{~d}, 2 \mathrm{H}, J=4.8 \mathrm{~Hz}), 4.19(\mathrm{~d}, 2 \mathrm{H}, J=4.8 \mathrm{~Hz})$, $3.92(\mathrm{~s}, 2 \mathrm{H}), 3.39-3.52(\mathrm{~m}, 4 \mathrm{H}), 2.74(\mathrm{~s}, 3 \mathrm{H}), 2.56(\mathrm{~s}, 3 \mathrm{H}), 2.45(\mathrm{~s}$, $3 \mathrm{H}), 1.08-1.23$ (m, 6H). Found: C, 63.37; H, 5.96; N, 9.89. Mass spectrum: $\mathrm{CI}, \mathrm{m} / \mathrm{z}, 551(\mathrm{M}+1)$.

\section{Radiochemistry}

Radioisotope Production. No-carrier-added aqueous ${ }^{18} \mathrm{~F}$-fluoride ion was produced on a PETtrace cyclotron (GE Healthcare) by irradiation of an $0.8-\mathrm{mL}$ silver-bodied water target with a 25 $\mu \mathrm{A}$ current and a $16.5-\mathrm{MeV}$ proton beam on $95 \%$ enriched ${ }^{18} \mathrm{O}$ $\mathrm{H}_{2} \mathrm{O}$ via the ${ }^{18} \mathrm{O}(\mathrm{p}, \mathrm{n}){ }^{18} \mathrm{~F}$ nuclear reaction.

Preparation of ${ }^{18} \mathrm{~F}$-Labeled $\mathrm{K}-\mathrm{F}$-Kryptofix-222 Complex. ${ }^{18} \mathrm{~F}$ Fluoride in ${ }^{18} \mathrm{O}-\mathrm{H}_{2} \mathrm{O}$ was transferred to a GE TRACERlab MX $\mathrm{FDG}_{\mathrm{F}}$ synthesizer and passed through an anion-exchange resin (Waters Sep-Pak Accell Light QMA cartridge in the carbonate form, prepared by washing with $10 \mathrm{~mL}$ of $0.5 \mathrm{M} \mathrm{K}_{2} \mathrm{CO}_{3}$ and then rinsing with $10 \mathrm{~mL}$ of water) under vacuum. Trapped ${ }^{18} \mathrm{~F}$-fluoride was eluted from the Sep-Pak cartridge and transferred to the reaction vessel with an eluent solution containing $\mathrm{K}_{2} \mathrm{CO}_{3}(7 \mathrm{mg}$ in $300 \mu \mathrm{L}$ of pure water), acetonitrile ( $300 \mu \mathrm{L})$, and $22 \mathrm{mg}$ of Kryptofix-222 (4,7,13,16,21,24-hexaoxa-1,10-diazabicyclo [8.8.8] hexacosane). Aliquots of acetonitrile were added, and the reaction mixture was evaporated to dryness after each addition $(3 \times 80 \mu \mathrm{L})$. The evaporation was performed at $95^{\circ} \mathrm{C}$ under nitrogen flow and vacuum.

Preparation and Formulation of ${ }^{18}$ F-DPA-714. Compound 2 (6 $\mathrm{mg}$ ) was dissolved in acetonitrile $(3 \mathrm{~mL})$, and the mixture was added to the dry ${ }^{18} \mathrm{~F}$-labeled K-F-Kryptofix-222 complex and allowed to react at $85^{\circ} \mathrm{C}$ for $5 \mathrm{~min}$. On completion, the reaction mixture was diluted with sterile water and passed through a $\mathrm{tC}_{18}$ cartridge (Waters Sep-Pak Accell Light $\mathrm{tC}_{18}$ cartridge, prepared by washing with $5 \mathrm{~mL}$ of ethanol and then rinsing with $10 \mathrm{~mL}$ of water). The reaction vessel was rinsed with sterile water, and the eluate again was passed through the $\mathrm{tC}_{18}$ cartridge. The trapped $\mathrm{tC}_{18}$-radiolabeled product was rinsed an additional 3 times with sterile water (total of $40 \mathrm{~mL}$ ). The product was eluted from the $\mathrm{tC}_{18}$ cartridge with ethanol $(2 \mathrm{~mL})$ and sterile water $(3 \mathrm{~mL})$. The resulting solution was passed though a $0.22-\mu \mathrm{m}$ Millipore CATHIVEX nonpyrogenic sterile filter to remove particulate material before highperformance liquid chromatography (HPLC) purification.

The crude mixture was injected into a Waters XTerra $\mathrm{RP} \mathrm{C}_{18} 10$ $\mu \mathrm{m}(7.8 \times 300 \mathrm{~mm})$ semipreparative reversed-phase HPLC column. With a mobile phase of $0.1 \mathrm{M}$ aqueous ammonium acetate $\left(\mathrm{NH}_{4} \mathrm{OAc}\right)(\mathrm{pH} \mathrm{10})$ and $\mathrm{CH}_{3} \mathrm{CN}(60: 40, \mathrm{v} / \mathrm{v})$ at a flow rate of 4.0 $\mathrm{mL} / \mathrm{min}$, the retention time $\left(\mathrm{t}_{\mathrm{R}}\right)$ of ${ }^{18} \mathrm{~F}-\mathrm{DPA}-714$ was determined to be $12 \mathrm{~min}$. The radioactive fraction corresponding to ${ }^{18} \mathrm{~F}-\mathrm{DPA}-714$ was collected and evaporated under vacuum with a rotary evaporator. The residue was reconstituted in sterile water $(4 \mathrm{~mL})$ and filtered through a $0.22-\mu \mathrm{m}$ Millipore GS $13-\mathrm{mm}$ sterile filter into a sterile pyrogen-free evacuated vial. Under these conditions, the $t_{R}$ of the tosylate precursor was determined to be greater than $35 \mathrm{~min}$.

Quality Control for ${ }^{18} F-D P A-714$. For the determination of specific radioactivity and radiochemical purity, a portion of the final solution with a known volume and radioactivity was injected into a Waters XTerra $C_{18} 5-\mu \mathrm{m}(4.6 \times 150 \mathrm{~mm})$ analytic reversedphase HPLC column. A mobile phase of $0.1 \mathrm{M}$ aqueous $\mathrm{NH}_{4} \mathrm{OAc}$ ( $\mathrm{pH} 10)$ and $\mathrm{CH}_{3} \mathrm{CN}(50: 50, \mathrm{v} / \mathrm{v})$ at a flow rate of $2.0 \mathrm{~mL} / \mathrm{min}$ was used to elute ${ }^{18} \mathrm{~F}-\mathrm{DPA}-714$ at $a t_{\mathrm{R}}$ of $2 \mathrm{~min}$. The area of the UV absorbance peak at $254 \mathrm{~nm}$ corresponding to the carrier product was measured (integrated) on the HPLC chromatogram and compared with a standard curve relating mass to UV absorbance. The $t_{R}$ of the tosylate precursor was determined to be greater than $20 \mathrm{~min}$.

\section{In Vitro Binding Affinity}

${ }^{3} \mathrm{H}-\mathrm{PK} 11195$ (specific activity, $\sim 322 \mathrm{GBq} / \mathrm{mmol}$ ) and ${ }^{3} \mathrm{H}-\mathrm{Ro} 15-$ 1788 (specific activity, $\sim 311 \mathrm{GBq} / \mathrm{mmol}$ ) were purchased from Dupont-New England Nuclear. For binding studies, mitochondria were prepared as previously described (28), with minor modifications as described here, from the kidneys of male Wistar rats killed by cervical dislocation. The kidneys were homogenized in 20

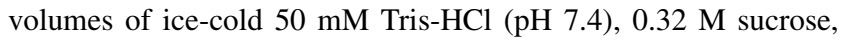
and $1 \mathrm{mM}$ ethylenediaminetetraacetic acid (buffer A) containing protease inhibitors (benzamidine at $160 \mu \mathrm{g} / \mathrm{mL}$, bacitracin at 200 $\mu \mathrm{g} / \mathrm{mL}$, and soybean trypsin inhibitor at $20 \mu \mathrm{g} / \mathrm{mL}$ ) with a Teflon (DuPont) pestle in a glass homogenizer and centrifuged at $600 \mathrm{~g}$ for $10 \mathrm{~min}$ at $4^{\circ} \mathrm{C}$. The resulting supernatant was centrifuged at $10,000 \mathrm{~g}$ for $10 \mathrm{~min}$ at $4^{\circ} \mathrm{C}$. The pellet was suspended in 20 volumes of icecold buffer A and centrifuged at $10,000 \mathrm{~g}$ for $10 \mathrm{~min}$ at $4^{\circ} \mathrm{C}$. The crude mitochondrial pellet was frozen at $-20^{\circ} \mathrm{C}$ until the time of the assay or incubated with $0.6 \mathrm{nM}{ }^{3} \mathrm{H}-\mathrm{PK} 11195$ in $50 \mathrm{mM}$ Tris- $\mathrm{HCl}$ ( $\mathrm{pH}$ 7.4) (buffer B) with a range of concentrations of the tested compounds $(0.1 \mathrm{nM}-10 \mu \mathrm{M})$ in a total volume of $0.5 \mathrm{~mL}$ for $90 \mathrm{~min}$ at $4^{\circ} \mathrm{C}$. The incubation was terminated by dilution to $5 \mathrm{~mL}$ with icecold buffer B; this step was followed immediately by rapid filtration through glass fiber Whatman GF/C filters. The filters were washed $(2.5 \mathrm{~mL}$ ) with buffer $\mathrm{B}$, and the amount of radioactivity retained on the filters was determined with a Packard 1600 TR liquid scintillation counter at $66 \%$ efficiency. Nonspecific binding was estimated for each sample in the presence of unlabeled $1 \mu \mathrm{M}$ PK11195. The $50 \%$ inhibitory concentrations were determined, and the dissociation constant $\left(\mathrm{K}_{\mathrm{i}}\right)$ values were derived according to a previously derived equation (29). The protein concentration was estimated by the method of Lowry et al. (30) with bovine serum albumin (SigmaAldrich) as the standard.

\section{Cell Culture}

Rat C6 glioma cells were cultured in Dulbecco's modified Eagle's medium supplemented with $10 \%$ fetal bovine serum, $2 \mathrm{mM}$ L-glutamine, penicillin at $100 \mathrm{U} / \mathrm{mL}$, and streptomycin at $100 \mu \mathrm{g} / \mathrm{mL}$. Cultures were maintained in a humidified atmosphere of $5 \% \mathrm{CO}_{2}$ and $95 \%$ air at $37^{\circ} \mathrm{C}$.

\section{Steroid Biosynthesis Assay}

PK11195, Ro5-4864, and clonazepam were obtained from Sigma. C6 cells were seeded in 24-well plates at a density of $\sim 10^{6}$ cells per well in a final volume of $1 \mathrm{~mL}$. Before the measurement of pregnenolone production, the cells were washed 3 times with a simple salt medium consisting of $140 \mathrm{mM} \mathrm{NaCl}$, $5 \mathrm{mM} \mathrm{KCl}, 1.8 \mathrm{mM} \mathrm{CaCl}_{2}, 1 \mathrm{mM} \mathrm{MgSO}_{4}, 10 \mathrm{mM}$ glucose, and $10 \mathrm{mM} N$-2-hydroxyethylpiperazine- $N^{\prime}$-2-ethanesulfonic acid (HEPES)-NaOH (pH 7.4) plus $0.1 \%$ bovine serum albumin. During the experiments, the cells were incubated with this simple salt medium in an air incubator at $37^{\circ} \mathrm{C}$. For the measurement of pregnenolone secreted into the medium, the further metabolism of pregnenolone was blocked by the addition of trilostane $(25 \mu \mathrm{M})$ 
and SU10603 $(10 \mu \mathrm{M})$ (inhibitors of 3 $\beta$-hydroxysteroid dehydrogenase and $17 \alpha$-hydroxylase, respectively) to the simple salt medium as previously described (31). The addition of DPA-714, of DPA-713, and of PK11195, Ro5-4864, or clonazepam to the C6 cells was accomplished by complete change of the simple salt medium to a medium containing the appropriate concentration (40 $\mu \mathrm{M})$ of the compound. The final concentration of ethanol was constant for all of the wells in each experiment and did not exceed $0.5 \%(\mathrm{v} / \mathrm{v})$, a concentration that, on its own, had no effect on steroid production. At the end of the incubation period $(2 \mathrm{~h})$, the cell medium was retained and centrifuged at $1,500 \mathrm{~g}$ for $10 \mathrm{~min}$. The amount of pregnenolone secreted into the medium was quantified by a radioimmunoassay with antipregnenolone antiserum (ICN Biochemicals Inc.) under the conditions recommended by the supplier. The cell protein concentration was measured by a previously described method (30).

\section{Measurement of Partition Coefficient (Log D)}

The $\log$ of the octanol-water partition coefficient (log D) was calculated (for DPA-713, DPA-714, and PK11195) with a previously described HPLC method (32). Phosphate buffer $(0.1 \mathrm{M})$ was prepared by dissolving weighed amounts of potassium dihydrogen orthophosphate in HPLC-grade water and adjusting the $\mathrm{pH}$ to 7.4 with sodium hydroxide solution $(0.1 \mathrm{M})$. Samples were analyzed with a $\mathrm{C}_{18}$ column (XTerra, $5 \mu \mathrm{m}, 150 \times 4.6 \mathrm{~mm}$ ) and a mobile phase of MeOH:phosphate buffer (pH 7.4) (60:40, v/v) at a flow rate of $1 \mathrm{~mL} / \mathrm{min}$. The lipophilicity of each compound was estimated by comparing its $t_{R}$ with those of standards having known $\log \mathrm{D}$ values. The standards used to generate a general calibration equation were aniline, benzene, bromobenzene, ethyl benzene, trimethyl benzene, and hexachlorobenzene dissolved in the mobile phase. All sample injections were performed 3 times, and the results were averaged to yield the final values. A calibration curve of $\log \mathrm{D}$ versus $t_{\mathrm{R}}$ was produced and resulted in an experimental calibration equation $\left(\mathrm{y}=1.0791^{0.7527 x}\right)$ with an $r^{2}$ of 0.995 . The exponential equation of the trend line function from the calibration graph and Excel (Microsoft) allowed the $\log \mathrm{D}$ values to be calculated.

\section{Ex Vivo Rodent ${ }^{18}$ F-DPA-714 Studies}

Adult male Wistar rats weighing 300-320 g (Janvier) were used for ex vivo experiments. All procedures were performed in accordance with the European Community Council Directive 86/ 609/EEC for the care of laboratory animals. Animals were kept on a 12-h light-dark cycle (temperature, $22.4^{\circ} \mathrm{C} \pm 0.5^{\circ} \mathrm{C}$ [mean \pm $\mathrm{SD}$; humidity, $40.3 \% \pm 7.2 \%$ ), and water and food were freely available.

Quinolinic Acid (QA) Lesions. Rats were anesthetized with isoflurane $(4 \%, 500 \mathrm{~mL} / \mathrm{min})$, placed on a stereotactic apparatus (Stoelting; Phymep), and maintained with isoflurane $(2 \%, 500$ $\mathrm{mL} / \mathrm{min}$ ) during surgery. The skull was exposed, and small holes were made with the use of a dental drill. Unilateral lesions were created in the right striatum at the following coordinates (millimeters from the bregma) (33): A, 0.7; L, -3; and P, -5.5. A cannula (gauge 25; Hamilton) was inserted into the holes in the skull, and a solution of QA (300 nmol in $2 \mu \mathrm{L}$ of phosphate buffer [pH 7.4]) was infused at a flow rate of $0.5 \mu \mathrm{L} / \mathrm{min}$. The syringe was left in place for $4 \mathrm{~min}$ before being removed to avoid a backflow of QA. The bone was filled in with wax, and the scalp was sutured.
Biodistribution Studies. Ex vivo biodistribution studies were performed with ${ }^{18} \mathrm{~F}$-DPA-714 $6 \mathrm{~d}$ after creation of the unilateral striatal QA lesions. Rats were injected via the penis vein with 20-37 $\mathrm{MBq}$ of ${ }^{18} \mathrm{~F}-\mathrm{DPA}-714$ in a mixture of water and ethanol $(85: 15)$ (control group, $n=6$ ); alternatively, rats were preinjected with PK11195 (5 mg/kg; $n=5)$, DPA-714 (1 mg/kg; $n=2)$, or DPA-713 $(1 \mathrm{mg} / \mathrm{kg} ; n=2) 15 \mathrm{~min}$ before the radioligand injection. Animals were sacrificed $60 \mathrm{~min}$ after the injection of ${ }^{18} \mathrm{~F}$-DPA-714. Samples of peripheral tissues (blood [taken via cardiac puncture, without anticoagulant], muscle, bone, liver, heart, and adrenal glands) and several brain areas (cerebellum, right and left striata, right and left frontal cortices, and right and left hippocampi) were removed and weighed. Radioactivity in these samples was measured with a $\gamma$-counter (2550 TR/LL; Packard). For peripheral tissues, the results are expressed as the ratio of the percentage injected dose per gram $(\% \mathrm{ID} / \mathrm{g})$ in tissue to the \%ID/g in blood \pm SEM. For brain areas, the results are expressed as the ratio of the $\% \mathrm{ID} / \mathrm{g}$ in the cerebral region to the $\% \mathrm{ID} / \mathrm{g}$ in the cerebellum $\pm \mathrm{SEM}$. The Student $t$ test was performed when the number of values was $\geq 5$. Statistical significance was set at a $P$ value of less than 0.05 .

Baboon ${ }^{18}$ F-DPA-714 PET Studies. A normal male Papio hamadryas baboon that was $13 \mathrm{y}$ old and weighed $23.1 \mathrm{~kg}$ was selected for PET. The baboon was maintained and handled in accordance with the National Health and Medical Research Council code of practice for the care and use of nonhuman primates for scientific purposes. Project application was approved by the Sydney South West Area Health Service Animal Ethics Committee.

All PET data were acquired with a Siemens Biograph lutetium oxyorthosilicate PET/CT scanner. This scanner yields a reconstructed PET spatial resolution of $6.3 \mathrm{~mm}$ full width at half maximum at the center of the field of view. The baboon was initially anesthetized intramuscularly with ketamine $(8 \mathrm{mg} / \mathrm{kg})$. Anesthesia was maintained with an intravenous infusion of ketamine (Parnell Laboratory) in saline at a ketamine dose rate of $0.2 \mathrm{mg} / \mathrm{kg} / \mathrm{min}$. The baboon also received $\mathrm{MgSO}_{4}(2 \mathrm{~mL}$ intravenously) administered over $30 \mathrm{~min}$ as well as atropine (1 mg intramuscularly) and metoclopramide (Maxolon; Mayne Pharma) (5 mg intramuscularly). The head of the baboon was immobilized with plastic tape to minimize motion artifacts. A CT scan of the head was completed before the emission study. Acquisition of the PET data in the list mode was commenced just before the intravenous administration of $100 \mathrm{MBq}$ of the radioligand in $4 \mathrm{~mL}$ of water for injection and was continued for $60 \mathrm{~min}$. The blocking study involved pretreatment with PK11195 (1.5 mg/kg intravenously) $5 \mathrm{~min}$ before radioligand injection, whereas in the displacement study, nonlabeled DPA-714 ( $1 \mathrm{mg} / \mathrm{kg}$ intravenously) was administered $20 \mathrm{~min}$ after the injection of ${ }^{18}$ F-DPA-714.

At the conclusion of each study, the list-mode data were sorted into a dynamic scan comprising 54 frames $(20 \times 30 \mathrm{~s}, 30 \times 60 \mathrm{~s}$, and $4 \times 300 \mathrm{~s}$ ). The dynamic 3-dimensional PET sinograms were rebinned with Fourier rebinning and reconstructed with filtered backprojection and CT data-based corrections for photon attenuation and scatter into 47 transaxial slices, each comprising $128 \times$ 128 voxels. Reconstructed voxel values in each frame are reported in units of $\mathrm{Bq} / \mathrm{mL}$, corrected for radioactive decay to the time of injection, and voxel dimensions were $0.206 \times 0.206 \times 0.337 \mathrm{~cm}$. Voxel values were then converted to units of percentage injected dose per volume $(\mathrm{mL})$ of brain tissue. An automated 3-dimensional registration algorithm was used to coregister the 2 reconstructed scans before region-of-interest definition. Time-activity 
curves representing variations in ligand concentrations versus time were constructed for the whole brain.

After the list-mode acquisition, a whole-body PET/CT scan was performed for $2 \mathrm{~min}$ at each of 6 bed positions to determine other sites of radioligand uptake.

\section{RESULTS}

\section{Chemistry}

DPA-714 and its tosylate analog (compound 2) were prepared as shown in Figure 1. Both compounds were synthesized for use in the radiolabeling process: DPA-714 as a nonlabeled standard to confirm correct product formation and the tosylate analog as a precursor for ${ }^{18} \mathrm{~F}$ labeling. In summary, Mitsunobu coupling of the phenolic pyrazolo[1,5a]pyrimidine (compound 1) (25) and 2-fluoroethanol in the presence of DIAD and triphenylphosphine in dry DMF afforded DPA-714 at a $47 \%$ yield. Initial attempts with tetrahydrofuran were unsuccessful because of the limited solubility of compound 1 in this solvent. Analogously, Mitsunobu coupling of compound 1 and toluene-4-sulfonic acid 2hydroxy-ethyl ester (the latter prepared by sulfonylation of 1,2-ethanediol in the presence of fresh silver oxide and a catalytic amount of potassium iodide) in the presence of DIAD and triphenylphosphine in dry DMF afforded the tosylate analog (compound 2) at an $85 \%$ yield.

\section{Radiochemistry}

DPA-714 was labeled with the positron emitter ${ }^{18} \mathrm{~F}$ (halflife: $109.8 \mathrm{~min}$ ) by nucleophilic aliphatic substitution (Fig. 1) with a GE TRACERlab MX ${ }_{\text {FDG }}$ synthesizer. ${ }^{18}$ F Fluorination was achieved by reaction of the tosylate precursor (compound 2) with cyclotron-produced ${ }^{18} \mathrm{~F}$-fluoride as an ${ }^{18} \mathrm{~F}$ labeled $\mathrm{K}-\mathrm{F}-\mathrm{Kryptofix}-222$ complex in acetonitrile at $85^{\circ} \mathrm{C}$ for $10 \mathrm{~min} .{ }^{18} \mathrm{~F}$-DPA-714 was purified by semipreparative reversed-phase HPLC. Total radiosynthesis time for the preparation of ${ }^{18} \mathrm{~F}$-DPA-714 was $40 \mathrm{~min}$. Initial attempts to produce ${ }^{18} \mathrm{~F}-\mathrm{DPA}-714$ with only $2.5 \mathrm{mg}$ of the tosylate precursor (compound 2) afforded the pure product at a $6 \%$ non-decay-corrected radiochemical yield. Increasing the amount of starting tosylate up to $12 \mathrm{mg}$ improved the process. The highest yields, $16 \%$ non-decay-corrected, were obtained with $6 \mathrm{mg}$ or more.

\section{In Vitro Binding}

The affinity of DPA-714 for the TSPO was evaluated by use of a membrane-binding assay with ${ }^{3} \mathrm{H}-\mathrm{PK} 11195$ as the radioligand and rat kidney tissue. To ensure the selectivity of DPA-714, its binding to the central benzodiazepine receptor (CBR) was assessed with ${ }^{3} \mathrm{H}-\mathrm{Ro} 15-1788$ and rat brain tissue. The affinity of DPA-714, $\mathrm{K}_{\mathrm{i}}=7.0 \pm 0.4 \mathrm{nM}$, was not as high as that of DPA-713, $\mathrm{K}_{\mathrm{i}}=4.7 \pm 0.2 \mathrm{nM}$, but was slightly higher than that of PK11195, $\mathrm{K}_{\mathrm{i}}=9.3 \pm 0.5 \mathrm{nM}$, in the same assay (Table 1). All 3 TSPO ligands, DPA-714, DPA-713, and PK11195, displayed negligible affinities for the CBR.

\section{In Vitro Steroid Biosynthesis Assay}

DPA-714 was assessed for its ability to increase pregnenolone synthesis by use of a well-developed steroidogenic assay (24). DPA-714 stimulated pregnenolone synthesis at levels $80 \%$ above the baseline, displaying significantly greater potency than PK11195. DPA-713 had no effect on steroidogenesis in the same assay (Fig. 2).

\section{Log D Determination}

The lipophilicities of DPA-714, DPA-713, and PK11195 were evaluated by use of HPLC. No column deterioration

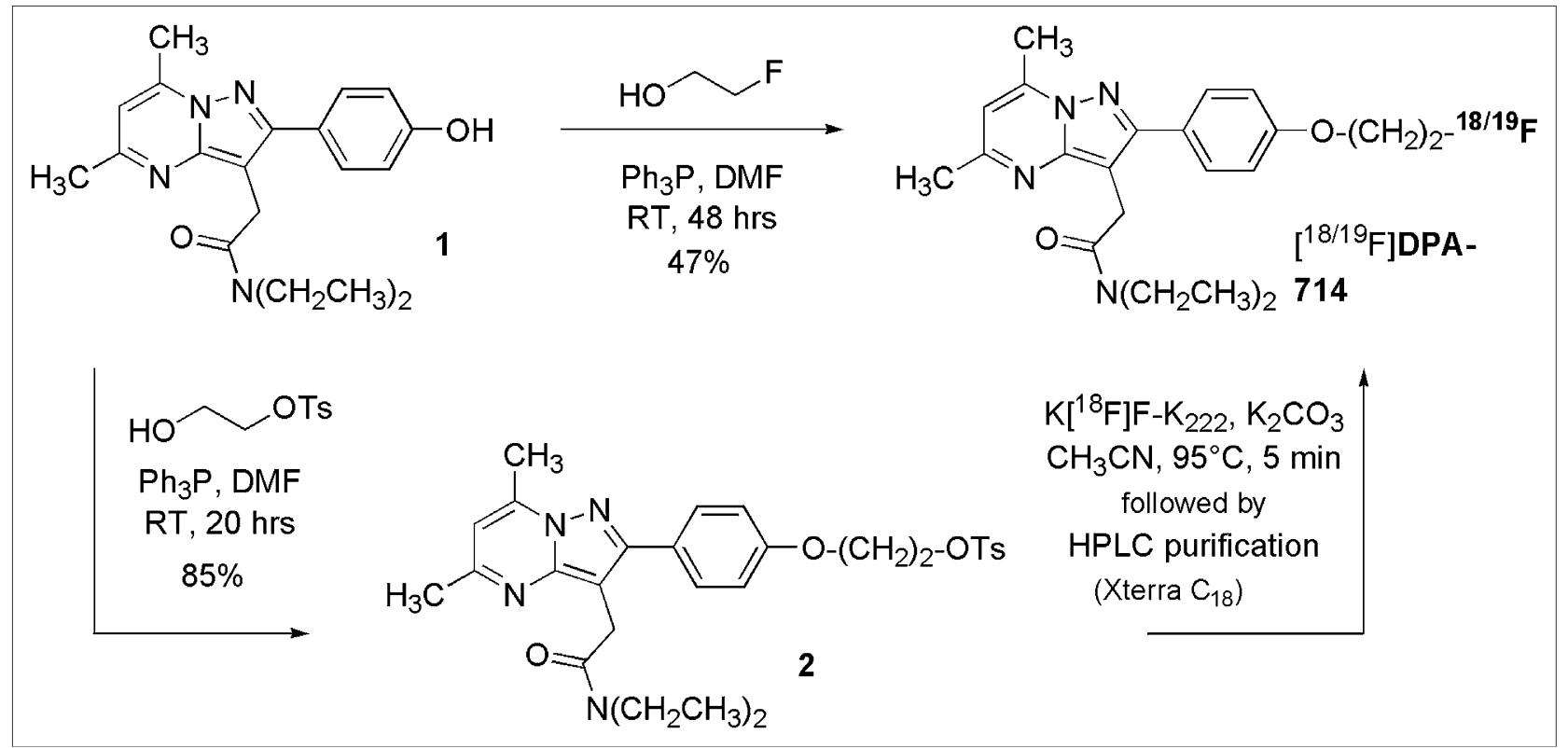

FIGURE 1. Chemical synthesis of DPA-714 and its tosylate derivative. $\mathrm{K}_{222}=$ Kryptofix-222; $\mathrm{OTs}=-\mathrm{OSO}_{2}\left(\mathrm{C}_{6} \mathrm{H}_{4}-p C H 3\right) ; \mathrm{Ph}_{3} \mathrm{P}=$ triphenylphosphine; RT = room temperature. 
TABLE 1

Affinities of Ligands for TSPO and CBR with ${ }^{3} \mathrm{H}-\mathrm{PK} 11195$ and Rat Kidney Membranes or ${ }^{3} \mathrm{H}-\mathrm{Ro15}-1788$ and Rat Brain Tissue as Receptor Sources, Respectively

\begin{tabular}{cccc}
\hline Ligand & $\begin{array}{c}\mathrm{K}_{i}(\mathrm{nM} \text {, mean } \pm \mathrm{SD}) \\
\text { for TSPO }\end{array}$ & $\begin{array}{c}\mathrm{K}_{\mathrm{i}}(\mathrm{nM}) \\
\text { for CBR }\end{array}$ & Log D \\
\hline DPA-714 & $7.0 \pm 0.4$ & $>10,000$ & 2.44 \\
DPA-713 & $4.7 \pm 0.2$ & $>10,000$ & 2.44 \\
PK11195 & $9.3 \pm 0.5$ & $>10,000$ & 3.35
\end{tabular}

Log D values for each ligand were determined by HPLC.

was observed for the duration of the experiments, and all measurements were obtained on the same day to minimize error. The $t_{R}$ values were recorded for the reference compounds, and a calibration graph was generated. DPA-714 and DPA-713 had the same $\log$ D value (2.44), which was lower than that of PK11195 (3.35) (Table 1).

\section{Rodent Studies}

Peripheral Biodistribution. Figure 3 shows the peripheral distribution of ${ }^{18} \mathrm{~F}$-DPA-714 in each of the 4 groups of rats with QA lesions (control and 3 pretreatment groups: PK11195, DPA-713, and DPA-714). The results for the control group showed that the highest accumulation of ${ }^{18} \mathrm{~F}$ DPA-714 was in the heart and adrenal glands, with only minimal accumulation in the bone, liver, and muscle. Rats pretreated with PK11195 (5 mg/kg) demonstrated significant inhibition of radioligand uptake in the heart, bone, and liver but not in the adrenal glands or muscle. In contrast, pretreatment with either DPA-714 (1 mg/kg) or DPA-713 (1 $\mathrm{mg} / \mathrm{kg}$ ) resulted in the inhibition of ${ }^{18} \mathrm{~F}$-DPA-714 uptake in the heart, liver, bone, and muscle and in partial blockade in the adrenal glands.

Cerebral Biodistribution. Figure 4 shows the cerebral distribution of ${ }^{18}$ F-DPA-714 in each of the 4 groups of rats

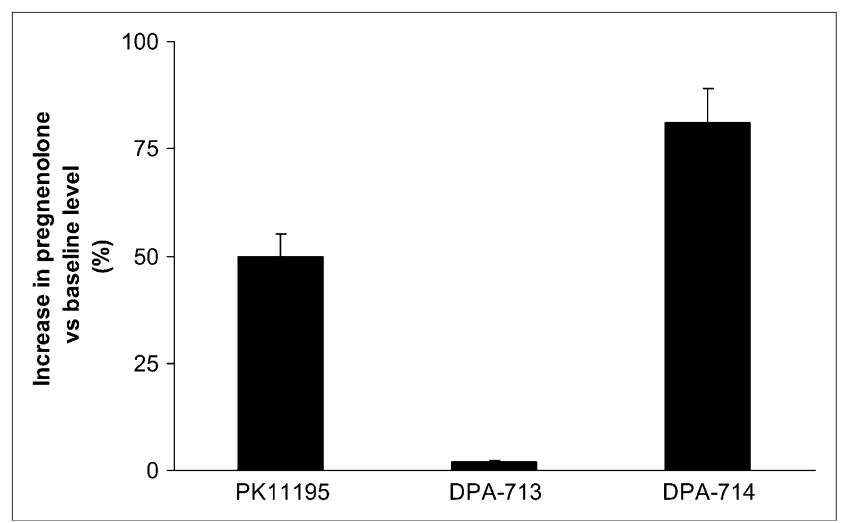

FIGURE 2. Effect of TSPO ligands on pregnenolone accumulation in rat $\mathrm{C} 6$ glioma cells. All compounds were used at same concentration $(40 \mu \mathrm{M})$. At end of incubation period $(2 \mathrm{~h})$, amount of pregnenolone was quantified by radioimmunoassay.

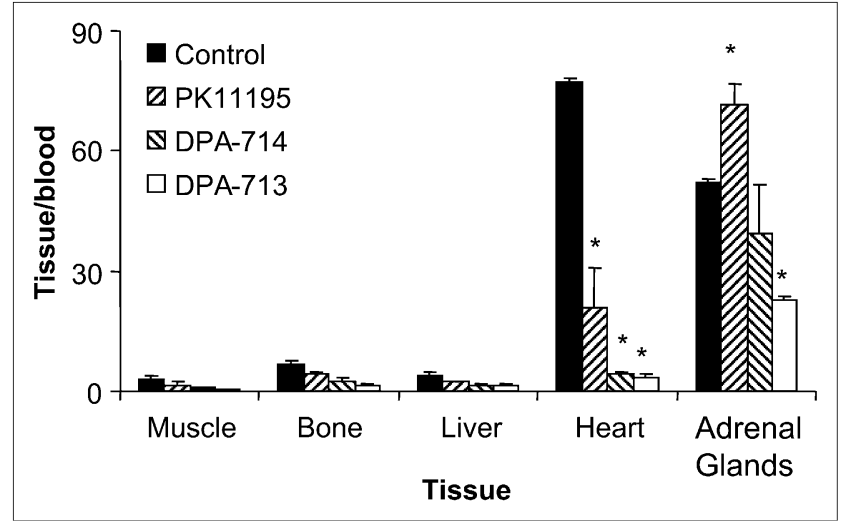

FIGURE 3. Uptake of ${ }^{18} \mathrm{~F}-\mathrm{DPA}-714$ (control) and effects of pretreatment with DPA-714, DPA-713, and PK11195 in various peripheral tissues of rats with QA lesions. ${ }^{18} \mathrm{~F}-\mathrm{DPA}-714$ uptake in each tissue is expressed relative to uptake in blood. ${ }^{\star} P<$ 0.05 .

with QA lesions. The results for the control group indicated a statistically significant increase in ${ }^{18} \mathrm{~F}$-DPA-714 uptake in the ipsilateral striatum $(4.81 \pm 0.47$ vs. $0.61 \pm 0.14 ; P<$ $0.05)$. The accumulation of ${ }^{18} \mathrm{~F}-\mathrm{DPA}-714$ in the ipsilateral

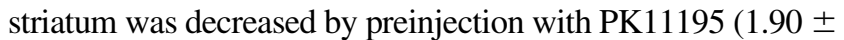
0.59 vs. $1.18 \pm 0.16 ; P<0.05)$. A visible decrease was also seen after preinjection with either DPA-714 (2.00 \pm 0.23 vs. $0.76 \pm 0.17)$ or DPA-713 (1.08 \pm 0.08 vs. $1.06 \pm$ $0.05)$.

\section{Baboon PET Studies}

PET studies were conducted with an anesthetized $P$. hamadryas baboon to evaluate the in vivo regional distribution kinetics of ${ }^{18}$ F-DPA-714. First, in a baseline study, dynamic PET brain imaging commenced a few minutes before the intravenous administration of ${ }^{18} \mathrm{~F}-\mathrm{DPA}-714(100 \mathrm{MBq}$ in $2 \mathrm{~mL}$ of saline; specific activity, $270 \mathrm{GBq} / \mu \mathrm{mol})$ and was terminated $60 \mathrm{~min}$ after injection. This acquisition was followed by a whole-body acquisition for $2 \mathrm{~min}$ at each of 6 bed positions. ${ }^{18} \mathrm{~F}-\mathrm{DPA}-714$ was capable of penetrating the blood-brain barrier, with accumulation in the brain (Fig. 5).

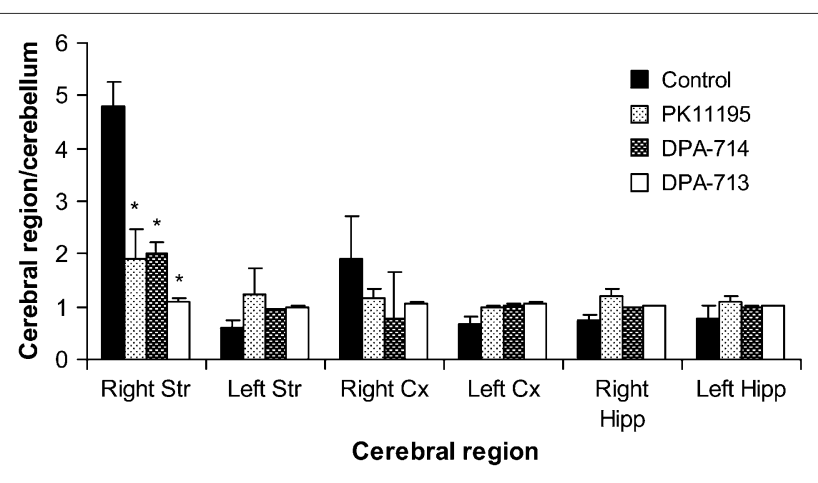

FIGURE 4. Uptake of ${ }^{18} \mathrm{~F}-\mathrm{DPA}-714$ (control) and effects of pretreatment with DPA-714, DPA-713, and PK11195 in various cerebral regions of rats with QA lesions. ${ }^{18} \mathrm{~F}-\mathrm{DPA}-714$ uptake in each region is expressed relative to uptake in cerebellum. ${ }^{\star} P<$ 0.05. $\mathrm{Cx}=$ cortex; Hipp = hippocampus; Str = striatum. 
Second, in a blockade study, pretreatment with the TSPO ligand PK11195 (1.5 mg/kg) was used to determine the specificity of ${ }^{18}$ F-DPA-714 uptake. PK11195 effectively blocked the uptake of ${ }^{18}$ F-DPA-714 in the brain (Fig. 5). Finally, a displacement study was conducted to assess the reversibility of radioligand binding. The displacement study involved the administration of nonlabeled DPA-714 (1 mg/kg) 20 min after the ${ }^{18}$ F-DPA-714 injection.

Time-activity curves representing the uptake of ${ }^{18} \mathrm{~F}$ DPA-714 in the whole baboon brain in each of the 3 PET studies are shown in Figure 6. In the baseline study, ${ }^{18} \mathrm{~F}$ DPA-714 uptake reached a maximum within $10 \mathrm{~min}$ and remained at approximately the same level for the following $50 \mathrm{~min}$. The results of the displacement study appeared to be analogous to those of the baseline study during the first 20 min; however, after the injection of nonlabeled DPA714 , the curve rose to a sharp peak followed by complete washout of the radioligand. In contrast, pretreatment with the TSPO-specific ligand PK11195 resulted in an initial increase in ${ }^{18} \mathrm{~F}$-DPA-714 uptake followed by a rapid decrease to the washout level, identical to that seen in the displacement study. The whole-body image visibly depicted the high uptake of ${ }^{18}$ F-DPA-714 in the heart, kidneys, adrenal glands, and salivary glands (Fig. 7A). The injection of nonlabeled DPA-714 20 min after radioligand administration led to the complete displacement of ${ }^{18}$ F-DPA-714 binding in these peripheral regions (Fig. 7B).

\section{DISCUSSION}

Over the last decade, TSPO ligand development has yielded a multitude of new high-affinity compounds (34); however, the range of PET ligands for the TSPO remains limited. ${ }^{11} \mathrm{C}$-PK11195 is still the most widely used PET tracer for TSPO studies, despite its deficiencies (19). Our goal has been to develop a TSPO-specific ligand with in vivo properties that are an improvement over or that are different from those of ${ }^{11} \mathrm{C}-\mathrm{PK} 11195$. In 2005, we reported the synthesis of the first TSPO-specific pyrazolopyrimidine radio- ligand, ${ }^{11} \mathrm{C}$-DPA-713 (25). Our current aim was to synthesize an ${ }^{18} \mathrm{~F}$-labeled derivative of DPA-713.

In vitro binding experiments with the fluorine analog DPA-714 demonstrated that substituting the methoxy moiety for the fluoroethoxy moiety had no adverse effect on the TSPO-binding affinity or lipophilicity (Table 1). Steroid assay results indicated that DPA-714 increased pregnenolone production with much greater potency $(80 \%$ above the baseline levels) than PK11195 and DPA-713 (50\% and 1\% above the baseline levels, respectively) (Fig. 2). This finding meant that although TSPO affinity was maintained after the exchange of methoxy for fluoroethoxy, the functional activity was effectively reversed. These results suggest a potential therapeutic role for DPA-714 in anxiety-based conditions. Further experiments are currently under way to evaluate this unexpected change in functional activity.

Rats with QA lesions showed high concentrations of ${ }^{18} \mathrm{~F}$ DPA-714 in TSPO-rich peripheral tissues, including the heart and adrenal glands (Fig. 3). Higher levels of ${ }^{18}$ F-DPA-714 in the ipsilateral striatum and cortex than in the contralateral striatum and cortex (Fig. 4) were consistent with the known ability of QA to increase TSPO expression (35). This increased uptake in lesion-containing brain areas indicated TSPO-specific binding because pretreatment of rats with PK11195, DPA-713, or DPA-714 before radioligand injection inhibited this uptake. ${ }^{18}$ F-DPA-714 uptake was also inhibited in most peripheral organs in rats in each pretreatment group, demonstrating TSPO-specific binding outside the brain. Interestingly, PK11195 failed to inhibit the binding of ${ }^{18} \mathrm{~F}$-DPA-714 in the adrenal glands, whereas a partial blockade was seen with both DPA-713 and DPA-714 (Fig. 3). These results may provide evidence for the existence of TSPO subtypes or splice variants, and this possibility is currently being evaluated in further studies. Overall, ${ }^{18} \mathrm{~F}-$ DPA-714 was observed to cross the rodent blood-brain barrier and specifically bind to the TSPO in areas of neuroinflammation.

The biodistribution and specificity of ${ }^{18}$ F-DPA-714 were further evaluated in a normal male P. hamadryas baboon in 3
FIGURE 5. $P$. hamadryas baboon PET summation images of selected transaxial brain slices over $60 \mathrm{~min}$.

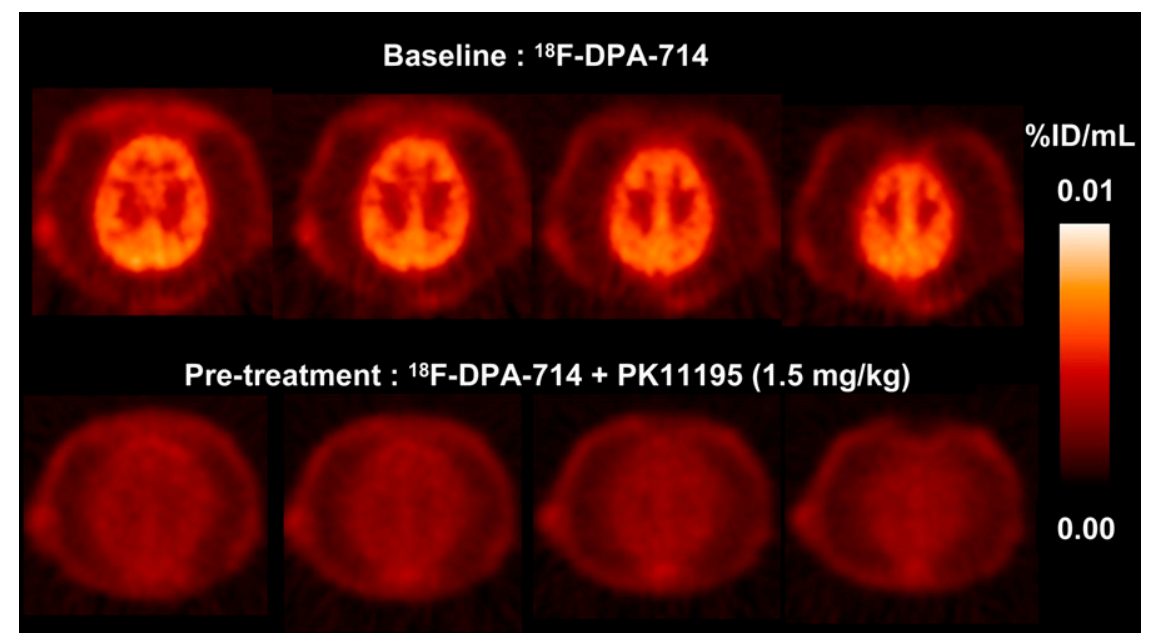




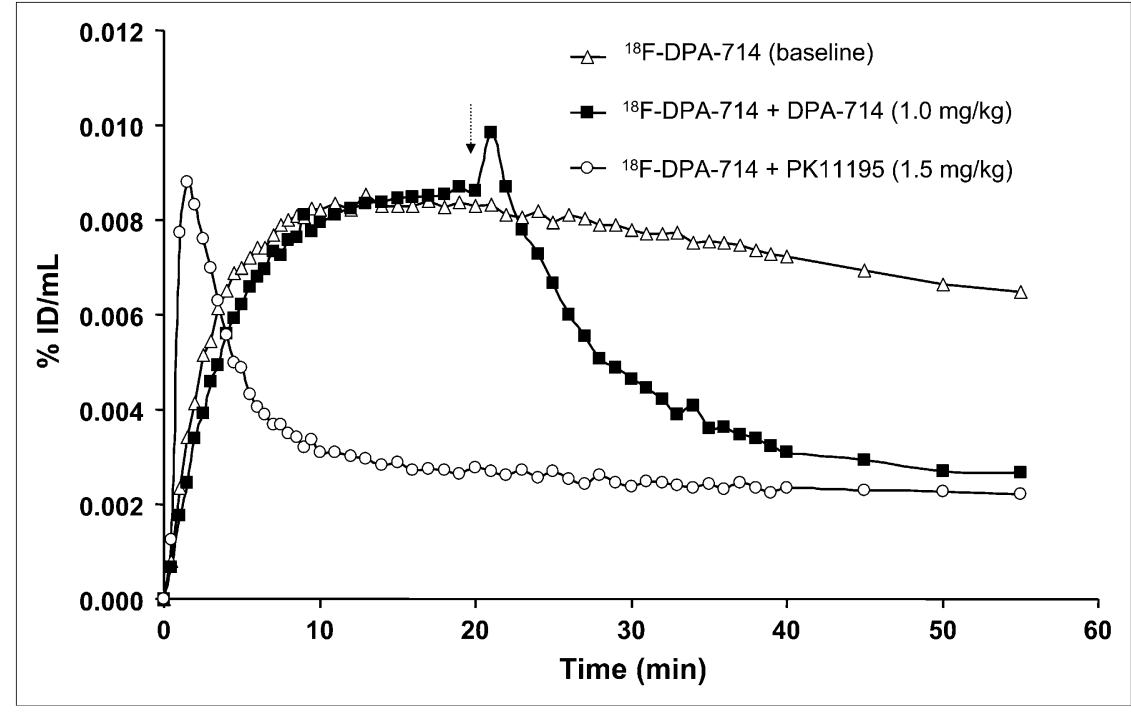

FIGURE 6. Time-activity curves depicting uptake of ${ }^{18} \mathrm{~F}-\mathrm{DPA}-714$ in whole $P$. hamadryas baboon brain during $60-\mathrm{min}$ PET scan time for all 3 studies: baseline ${ }^{18} \mathrm{~F}-\mathrm{DPA}-714$, block ${ }^{18} \mathrm{~F}-\mathrm{DPA}-714$ plus PK11195 (1.5 mg/kg), and displacement 18F-DPA-714 plus DPA-714 (1 mg/kg). Arrow indicates time of administration of displacing agent. separate PET experiments. The results of the baseline study indicated rapid blood-brain barrier penetration and good uptake of the radioligand in the baboon brain (Fig. 5). Pretreatment with PK11195 resulted in the complete inhibition of ${ }^{18} \mathrm{~F}$-DPA-714 uptake in the brain, suggesting that the uptake observed represented specific binding to TSPO. The whole-body image (Fig. 7A) depicted marked radioligand uptake in TSPO-rich regions similar to that seen in rodent studies. Figure 7B demonstrated the ease with which nonlabeled DPA-714 displaced ${ }^{18}$ F-DPA-714 in the heart and kidneys, denoting TSPO-specific binding outside the brain. ${ }^{18} \mathrm{~F}$-DPA-714 has yet to be evaluated concurrently with other TSPO-specific radioligands, such as ${ }^{11} \mathrm{C}-\mathrm{DAA} 1106$ and ${ }^{18} \mathrm{~F}$ FEDAA1106; however, the shapes of their respective timeactivity curves appear to be remarkably similar to that of ${ }^{18}$ F-DPA-714 (23,36). All 3 time-activity curves display rapid brain uptake, good retention, and effective displacement after the injection of the nonlabeled ligand. The only

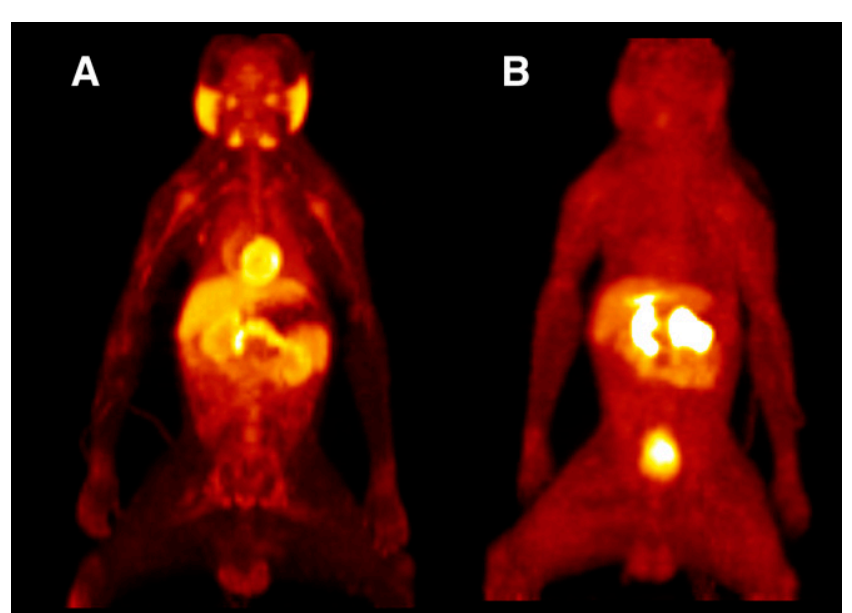

FIGURE 7. PET images of whole $P$. hamadryas baboon body 60 min after intravenous injection of ${ }^{18} \mathrm{~F}-\mathrm{DPA}-714$ (baseline) $(\mathrm{A})$ and ${ }^{18} \mathrm{~F}-\mathrm{DPA}-714$ plus DPA-714 (1.0 mg/kg) (B). difference is that ${ }^{18} \mathrm{~F}$-DPA-714 takes slightly longer to reach maximum brain uptake and hence may possess slower kinetics than ${ }^{11} \mathrm{C}$-DAA1 106 or ${ }^{18} \mathrm{~F}$-FEDAA1106 in nonhuman primates. Future studies should involve the evaluation of all 3 radioligands in separate PET experiments with the same subject to enable meaningful comparisons.

\section{CONCLUSION}

Taken together, these results indicate that ${ }^{18} \mathrm{~F}-\mathrm{DPA}-714$ is a high-affinity radioligand specific for the TSPO. Its suitable in vivo properties and ability to bind to the TSPO with high specificity, along with its significant effect on steroid synthesis, make this ligand an attractive tool for evaluating the TSPO in neuroinflammatory processes.

\section{ACKNOWLEDGMENT}

This study was funded in part by the EC-FP6 project DiMI, LSHB-CT-2005-512146.

\section{REFERENCES}

1. Anholt RR, Pedersen PL, De Souza EB, Snyder SH. The peripheral-type benzodiazepine receptor: localization to the mitochondrial outer membrane. J Biol Chem. 1986;261:576-583.

2. Casellas P, Galiegue S, Basile AS. Peripheral benzodiazepine receptors and mitochondrial function. Neurochem Int. 2002;40:475-486.

3. Braestrup C, Squires R. Specific benzodiazepine receptors in rat brain characterized by high-affinity $\left[{ }^{3} \mathrm{H}\right]$ diazepam binding. Proc Natl Acad Sci USA. 1977;74:3805-3809.

4. Papadopoulos V, Baraldi M, Guilarte TR, et al. Translocator protein (18 kDa): new nomenclature for the peripheral-type benzodiazepine receptor based on its structure and molecular function. Trends Pharmacol Sci. 2006;27:402-409.

5. Chelli B, Lena A, Vanacore R, et al. Peripheral benzodiazepine receptor ligands: mitochondrial transmembrane potential depolarization and apoptosis induction in rat C6 glioma cells. Biochem Pharmacol. 2004;68:125-134.

6. Alho H, Varga V, Krueger KE. Expression of mitochondrial benzodiazepine receptor and its putative endogenous ligand diazepam binding inhibitor in cultured primary astrocytes and C-6 cells: relation to cell growth. Cell Growth Differ. 1994;5:1005-1014. 
7. Zavala F. Benzodiazepines, anxiety and immunity. Pharmacol Ther. 1997;75: 199-216.

8. Taketani S, Kohno H, Furukawa T, Tokunaga R. Involvement of peripheral-type benzodiazepine receptors in the intracellular transport of heme and porphyrins. J Biochem (Tokyo). 1995;117:875-880.

9. Papadopoulos V, Amri H, Boujrad N, et al. Peripheral benzodiazepine receptor in cholesterol transport and steroidogenesis. Steroids. 1997;62:21-28.

10. Liu J, Rone M, Papadopoulos V. Protein-protein interactions mediate mitochondrial cholesterol transport and steroid biosynthesis. J Biol Chem. 2006;281: 38879-38893.

11. Primofiore G, Da Settimo F, Taliani S, et al. N,N-Dialkyl-2-phenylindol-3ylglyoxylamides: a new class of potent and selective ligands at the peripheral benzodiazepine receptor. J Med Chem. 2004;47:1852-1855.

12. Costa E, Guidotti A. Diazepam binding inhibitor (DBI): a peptide with multiple biological actions. Life Sci. 1991;49:325-344.

13. Gavish M, Bachman I, Shoukrun R, et al. Enigma of the peripheral benzodiazepine receptor. Pharmacol Rev. 1999;51:629-650.

14. Galiegue S, Tinel N, Casellas P. The peripheral benzodiazepine receptor: a promising therapeutic drug target. Curr Med Chem. 2003;10:1563-1572.

15. Myers R, Manjil LG, Cullen BM, Price GW, Frackowiak RS, Cremer JE. Macrophage and astrocyte populations in relation to $\left[{ }^{3} \mathrm{H}\right] \mathrm{PK} 11195$ binding in rat cerebral cortex following a local ischaemic lesion. J Cereb Blood Flow Metab. 1991;11:314-322.

16. Banati R. Visualising microglial activation in vivo. Glia. 2002;40:206-217.

17. Gonzalez-Scarano F, Baltuch G. Microglia as mediators of inflammatory and degenerative diseases. Annu Rev Neurosci. 1999;22:219-240.

18. Venneti S, Lopresti B, Wiley C. The peripheral benzodiazepine receptor in microglia: from pathology to imaging. Prog Neurobiol. 2006;80:308-322.

19. Lockhart A, Davis B, Matthews JC, et al. The peripheral benzodiazepine receptor ligand PK11195 binds with high affinity to the acute phase reactant $\alpha 1$ acid glycoprotein: implications for the use of the ligand as a CNS inflammatory marker. Nucl Med Biol. 2003;30:199-206.

20. Zhang MR, Maeda J, Furutsuka K, et al. $\left[{ }^{18} \mathrm{~F}\right]$ FMDAA1106 and $\left[{ }^{18} \mathrm{~F}\right] \mathrm{FE}-$ DAA1106: two positron-emitter labeled ligands for peripheral benzodiazepine receptor (PBR). Bioorg Med Chem Lett. 2003;13:201-204.

21. Imaizumi M, Kim H-J, Zoghbi S, et al. PET imaging with ${ }^{11} \mathrm{C}-\mathrm{PBR} 28$ can localize and quantify upregulated peripheral benzodiazepine receptors associated with cerebral ischemia in rat. Neurosci Lett. 2007;411:200-205.

22. Zhang MR, Maeda J, Ogawa M, et al. Development of a new radioligand, $N$-(5fluoro-2-phenoxyphenyl)- $N$-(2-[ $\left.{ }^{18} \mathrm{~F}\right]$ fluoroethyl-5-methoxybenzyl)acetamide, for PET imaging of peripheral benzodiazepine receptor in primate brain. $J$ Med Chem. 2004;47:2228-2235.
23. Fujimura Y, Ikoma Y, Yasuno F, et al. Quantitative analyses of ${ }^{18}$ F-FEDAA1106 binding to peripheral benzodiazepine receptors in living human brain. $\mathrm{J} \mathrm{Nucl}$ Med. 2006;47:43-50.

24. Selleri S, Bruni F, Costagli C, et al. 2-Arylpyrazolo[1,5-a]pyrimidin-3-yl acetamides: new potent and selective peripheral benzodiazepine receptor ligands. Bioorg Med Chem. 2001;9:2661-2671.

25. James M, Fulton R, Henderson D, et al. Synthesis and in vivo evaluation of a novel peripheral benzodiazepine receptor PET radioligand. Bioorg Med Chem. 2005;13:6188-6194.

26. Thominiaux C, Dollé F, James ML, et al. Improved synthesis of the peripheral benzodiazepine receptor ligand $\left[{ }^{11} \mathrm{C}\right] \mathrm{DPA}-713$ using $\left[{ }^{11} \mathrm{C}\right]$ methyl triflate. Appl Radiat Isot. 2006;64:570-573.

27. Boutin H, Chauveau F, Thominiaux C, et al. ${ }^{11} \mathrm{C}-\mathrm{DPA}-713$ : a novel peripheral benzodiazepine receptor PET ligand for in vivo imaging of neuroinflammation. J Nucl Med. 2007;48:573-581.

28. Trapani G, Franco M, Ricciardi L, et al. Synthesis and binding affinity of 2-phenylimidazo[1,2- $\alpha]$ pyridine derivatives for both central and peripheral benzodiazepine receptors: a new series of high-affinity and selective ligands for the peripheral type. J Med Chem. 1997;40:3109-3118.

29. Cheng Y, Prusoff WH. Relationship between the inhibition constant (K1) and the concentration of inhibitor which causes 50 per cent inhibition (I50) of an enzymatic reaction. Biochem Pharmacol. 1973;22:3099-3108.

30. Lowry OH, Rosebrough NJ, Farr AL, Randall RJ. Protein measurement with the Folin phenol reagent. J Biol Chem. 1951;193:265-275.

31. Campiani G, Nacci V, Fiorini I, et al. Synthesis, biological activity, and SARs of pyrrolobenzoxazepine derivatives, a new class of specific "peripheral-type" benzodiazepine receptor ligands. J Med Chem. 1996;39:3435-3450.

32. Waterhouse R, Mardon K, Giles K, Collier T, O’Brien J. Halogenated 4(phenoxymethyl)piperidines as potential radiolabeled probes for s-1 receptors: in vivo evaluation of [123I]-1-(iodopropen-2-yl)-4-[(4-cyanophenoxy)methyl]piperidine. J Med Chem. 1997;40:1657-1667.

33. Paxinos G, Watson C. The Rat Brain in Stereotaxic Coordinates. 2nd ed. Sydney, New South Wales, Australia: Academic Press; 1986.

34. James M, Selleri S, Kassiou M. Development of ligands for the peripheral benzodiazepine receptor. Curr Med Chem. 2006;13:1991-2001.

35. Ryu JK, Choi HB, McLarnon JG. Peripheral benzodiazepine receptor ligand PK11195 reduces microglial activation and neuronal death in quinolinic acidinjected rat striatum. Neurobiol Dis. 2005;20:550-561.

36. Maeda J, Suhara T, Zhang MR, et al. Novel peripheral benzodiazepine receptor ligand $\left[{ }^{11} \mathrm{C}\right] \mathrm{DAA} 1106$ for PET: an imaging tool for glial cells in the brain. Synapse. 2004;52:283-291. 